\title{
Paracetamol versus Paracetamol Plus Ondansetron on Acute Postoperative Pain
}

\author{
Mohamad Aryafar, MD ${ }^{1}$ Mahnaz Narimani Zamanabadi, MD ${ }^{1} \quad$ Kourosh Farazmehr, MD ${ }^{1}$ \\ Giti Dehghanmanshadi, MD ${ }^{1}$ Sepideh Davoodinejad, MD² Farshid Cholami, MD ${ }^{1}$ \\ ${ }^{1}$ Department of Anesthesiology, Faculty of Medicine, Tehran Medical \\ Sciences, Islamic Azad University, Tehran, Iran \\ ${ }^{2}$ Student of Research Committee, Tehran Medical Sciences, Islamic \\ Azad University, Tehran, Iran \\ Address for correspondence Farshid Gholami, Assistant Professor, \\ Clinical Research and Development Center of Bou-Ali Hospital, Tehran \\ Medical Sciences Branch, Islamic Azad University, Tehran, Iran \\ (e-mail: dr.gholami.f@gmail.com).
}

Surg J (NY) 2021;7:e314-e318.

\author{
Abstract \\ Keywords \\ - postoperative pain \\ - ondansetron \\ - paracetamol \\ - abdominal surgeries \\ - analgesic use \\ - severity
}

This study was performed to determine the comparative efficacy of paracetamol alone versus paracetamol plus ondansetron on acute postoperative pain after abdominal surgeries in Azad University hospitals in 2017 and 2019. In this randomized clinical trial, 62 consecutive patients under abdominal surgeries, were randomly divided into two groups, group 1 patient who received paracetamol alone 1 gram and group 2 patient who received paracetamol 1 gram plus $4 \mathrm{mg}$ ondansetron and the pain severities were determined and compared between groups at recovery and after 4 and 24 hours. The results of this study revealed that there were no statistically significant differences between two groups for the postoperative pain severity and analgesic use $(p>0.05)$. It may be concluded that addition of ondansetron to paracetamol would not result in further postoperative pain reduction and additive use of this drug is not recommended.

Pain is one of the problems that always harms the person and has many unwanted side effects. According to the definition of the International Association for the Study of Pain (IASP), pain is an unpleasant emotional and sensory experience with potential or actual tissue damage. ${ }^{1}$ Meanwhile, ${ }^{2}$ one of the worst pain that humans endure is acute postoperative pain and the pain is more severe, it creates hemodynamic and metabolic responses to patients., ${ }^{3,4}$ About $21 \%$ of patients' experience moderate to severe pain after surgery. ${ }^{5}$ Insufficient relief of postoperative pain leads to complications such as long recovery, ${ }^{6}$ long admission, increased hospital costs, and reduced patient satisfaction. ${ }^{7}$ Effective management of postoperative pain is now part of the surgical process and not only reduces the suffering of the patient but also reduces mortality and promotes rapid improvement and early discharge from the hospital, ${ }^{8}$ improves the patient's quality of life, and reduces costs. ${ }^{9}$ Effective management of postopera-

received

September 3, 2019 accepted after revision July 26, 2021 tive pain involves a multimodal approach in which different drugs are used with different mechanisms and methods of administration. ${ }^{10}$ Today, there are various treatments for reducing postoperative pain, each with its own effectiveness and success, ${ }^{11}$ which include prescribing synthetic drugs and opioid drugs before or during surgery. ${ }^{12}$ Opioids are dosedependent, with side effects such as nausea and vomiting, itching, urinary retention, respiratory depression, and consequently increased hospitalization time. ${ }^{13}$ But the use of nonopioid analgesics reduces side effects. ${ }^{14}$ Long-term administration with high doses of analgesics may cause bleeding at the site of gastrointestinal bleeding and renal failure, and nonopioid analgesics do not have these complications. ${ }^{15,16}$ Accordingly, in this study, we compared the effect of paracetamol alone or paracetamol plus endonestrone one on acute pain after abdominal surgery in hospitals of Islamic Azad University in 2017 and 2019.

\section{(C) 2021. The Author(s).}

This is an open access article published by Thieme under the terms of the Creative Commons Attribution License, permitting unrestricted use, distribution, and reproduction so long as the original work is properly cited. (https://creativecommons.org/licenses/by/4.0/) Thieme Medical Publishers, Inc., 333 Seventh Avenue, 18th Floor, New York, NY 10001, USA 


\section{Methods}

This study was a randomized clinical trial study in patients undergoing elective abdominal surgery. The inclusion criteria for this study were elective surgery, individual consent for participation in the study, no history of paracetamol and ondansetron susceptibility, age 20 to 60 years, body mass index (BMI) 20 to 30, tendency to general anesthesia, grade 1 and 2 American Society of Anesthesiologists (ASA), and no history of drug addiction. The exclusion criteria for this study were history of surgery for more than three hours, lack of patient collaboration due to postoperative delirium, complication of surgery, and use of postoperative supplements. After obtaining written consent from patients who underwent elective abdominal surgery and had ASA Classes 1 and 2 , they were randomly divided into two groups: group 1 : patient who received paracetamol alone 1 gram and group 2 : patient who received paracetamol 1 gram plus $4 \mathrm{mg}$ ondansetron. The patients were unaware regarding the type of intervention.

In both groups after induction with fentanyl $2 \mu \mathrm{g} / \mathrm{kg}$, midazolam $0.05 \mathrm{mg} / \mathrm{kg}$, atracurium $0.5 \mathrm{mg} / \mathrm{kg}$, each hour 0.5 to $1 \mu \mathrm{g} / \mathrm{kg}$ fentanyl and the patients were intubated using tracheal tube (tracheal tube of 7 or 7.5 for the female and tracheal tube 7.5 or 8 for men). To maintain anesthesia, oxygen and nitroxide were used in equal ratio $(50 \%$ each) plus propofol 6 to $12 \mathrm{mg} / \mathrm{kg} / \mathrm{h}$. Each hour $0.001 \mathrm{mg} / \mathrm{kg}$ fentanyl and $0.2 \mathrm{mg} / \mathrm{kg}$ atracurium were administered to patients.

At the end of the surgery, muscle relaxant drugs were reversed with neostigmine $0.04 \mathrm{mg} / \mathrm{kg}$ and atropine 0.02 $\mathrm{mg} / \mathrm{kg}$. Extubation of tracheal tubes was taken after returning gag reflux to normal situation.

It should be noted that in the first group, 1 gram of paracetamol was injected intravenously within 20 minutes for patients at the end of the operation. In the second group, ondansetron was given $4 \mathrm{mg}$ and 30 minutes before the end of the intravenous operation, and at the end of the operation, 1 gram of paracetamol was injected intravenously and administered in 20 minutes to patients.

Patients' pain was then assessed by a trained nurse at the time of recovery, 4 hours and 24 hours after the operation, and recorded in the questionnaire. Additionally, the opioid drug was recorded in the questionnaire within 24 hours of operation, and then the two groups were compared by statistical analysis. Collected data was evaluated using checklist and field survey. The clinician responsible for collecting the data was oblivious regarding the type of intervention till the end of the study.

Data were analyzed using SPSS software version 13. For quantitative data, mean, and standard deviations were recorded. Absolute and relative frequency were recorded for qualitative variables. The tests were Chi-square, T-independent, and Fisher, and the level of significance was $<0.05$.

T-test of two independent samples was used to evaluate the effect of adding ondansetron to paracetamol to improve postoperative pain. Power analysis was used to evaluate the adequacy of the sample size. Power analysis was performed using pwr package. ${ }^{17}$ under $\mathrm{R}$ software under two different conditions (- Supplementary Figs. $\mathbf{S 1}$ and $\mathbf{S 2}$ [available online only]). Using significance level 0.1, the results showed that with a sample size of 62 people (31 people with paracetamol plus ondansetron and 31 people with paracetamol) with appropriate power, moderate to high pain relief in the group paracetamol plus ondansetron can test the outcomes of paracetamol. Using significance level 0.05 , a sample size of 62 people can be used to compare the pain between two groups with a large effect size. ${ }^{18}$

This study was approved by the Research Ethics Committee Board at the (Tehran Medical Sciences, Islamic Azad University, Tehran, Iran) and was in accordance with the Helsinki principles.

\section{Results}

The distribution of age, gender, BMI, ASA class, and type of surgery were identical in two groups ( $p$-values were as follows: $p=0.872, p=0.793, p=0.855, p=0.199$, and $p=0.316$, respectively).

There was no statistically significant difference between the two groups in the number of opioids administered intraoperatively $(p=0.221)$. Fig. 1 shows the intraoperative opioid dose in patients receiving paracetamol alone and those who received paracetamol with ondansetron. Also, there was no statistically significant difference between the two groups in the postoperative drug dose $(p=0.839)$. - Fig. 2 shows the postoperative opioid dose in patients receiving paracetamol alone and those who received paracetamol with ondansetron.

The severity of pain at the time of recovery was similar in two groups $(p=0.653)$. This similarity is shown in - Fig. 3 . Furthermore, the severity of pain after 4 hours was not statistically significant between the two groups $(p=0.162)$, as is shown in - Fig. 4 . Also, the severity of pain after 24 hours in the two groups was not statistically significant $(p=0.083)$, which is depicted in $\boldsymbol{- F i g . ~} \mathbf{5}$.

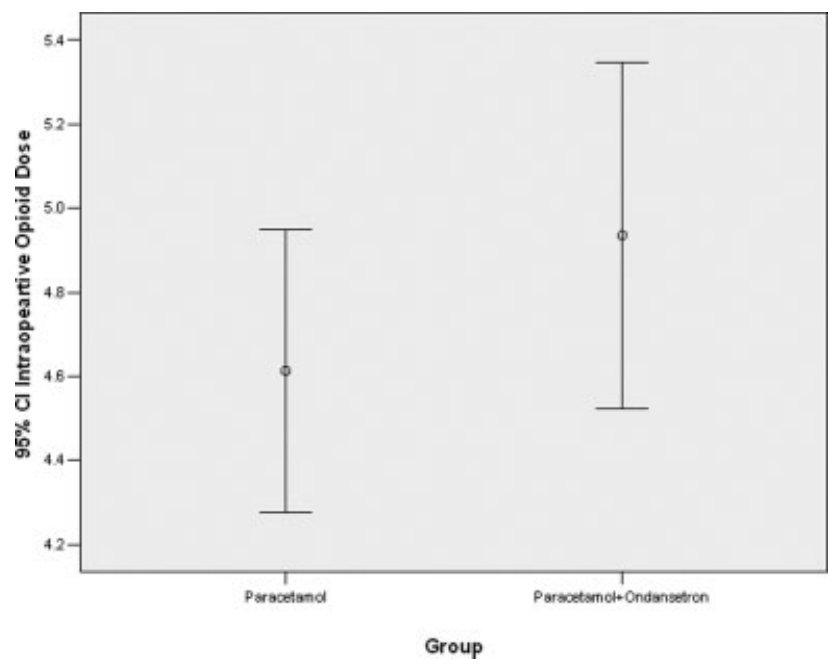

Fig. 1 The intraoperative opioid dose in patients receiving paracetamol alone and those who received paracetamol with ondansetron. 


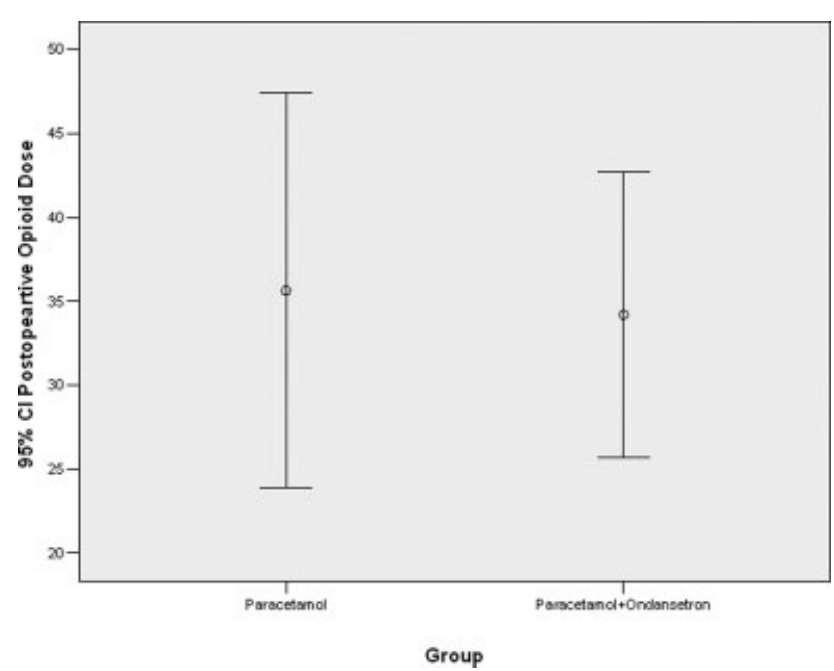

Fig. 2 The postoperative opioid dose in patients receiving paracetamol alone and those who received paracetamol with ondansetron.

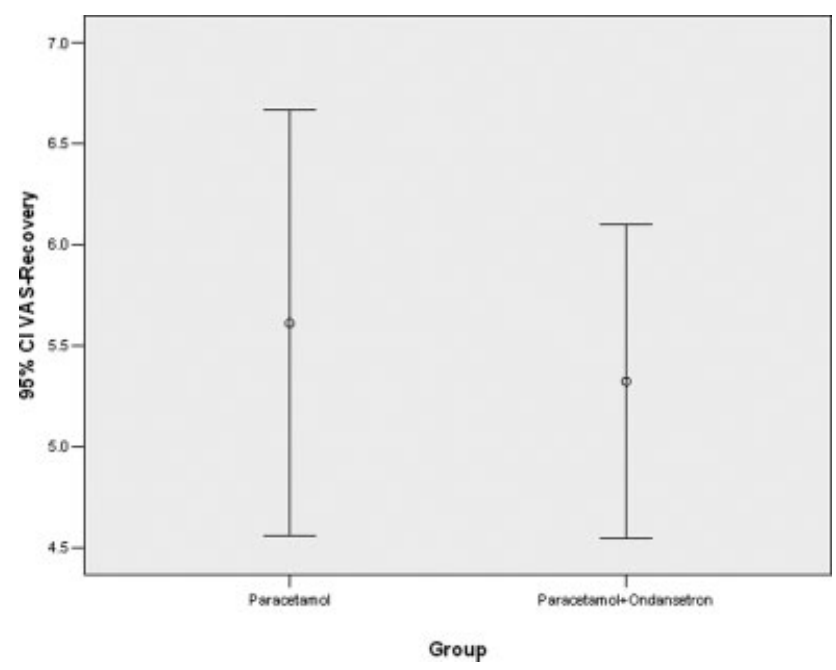

Fig. 3 Showing the severity of pain at the time of recovery in patients receiving paracetamol alone and those who received paracetamol with ondansetron.

\section{Discussion}

Nowadays, there are several treatments to reduce pain after surgery, each with its own effectiveness and success. ${ }^{16},{ }^{17}$ Opioids are dose-dependent, with side effects such as nausea and vomiting, ileus, itching, urinary retention, respiratory depression, and consequently increased hospitalization time. ${ }^{18}$ But the use of nonopioid analgesics reduces side effects. ${ }^{19}$ Long-term administration with high doses of analgesics may cause bleeding at the site of gastrointestinal bleeding and renal failure, and nonopioid analgesics do not have these complications. ${ }^{20}$ Accordingly, in this study, we compared the effect of paracetamol alone or paracetamol with ondansetron on acute pain after abdominal surgery in hospitals of Islamic Azad University in 2016 to 2017.

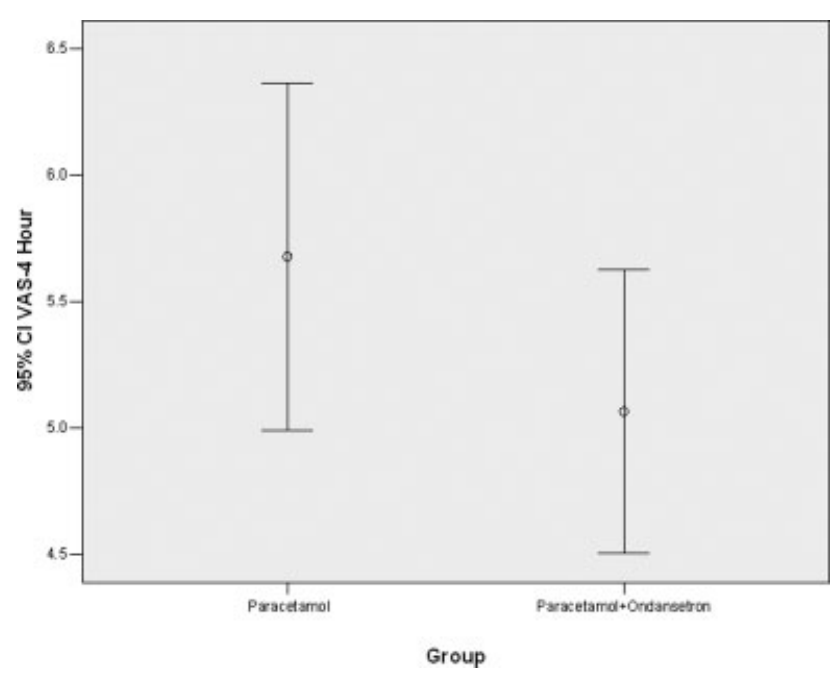

Fig. 4 Showing the severity of pain after 4 hours in patients receiving paracetamol alone and those who received paracetamol with ondansetron.

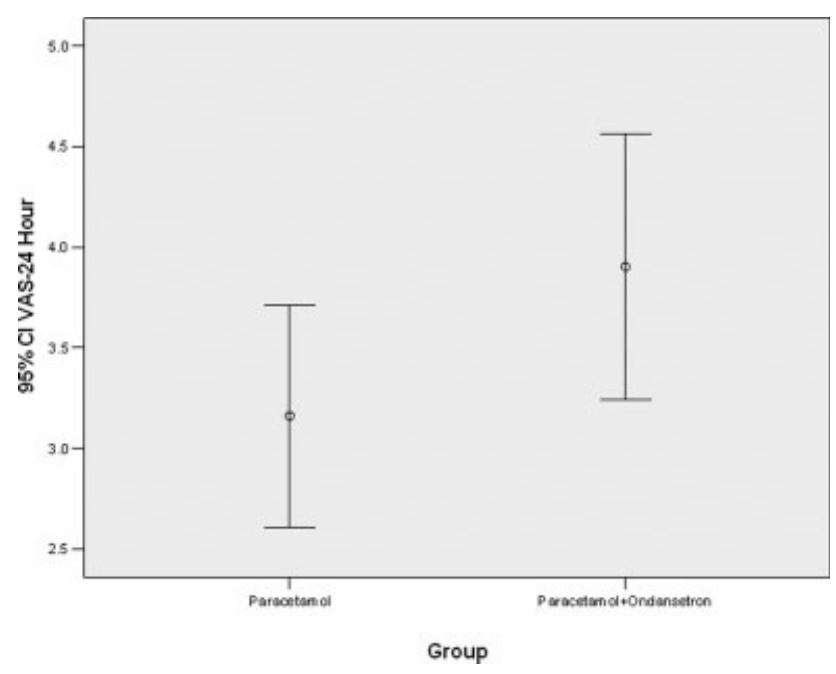

Fig. 5 Showing the severity of pain after 24 hours in patients receiving paracetamol alone and those who received paracetamol with ondansetron.

The results of this study showed that the severity of postoperative pain in recovery and at 4 and 24 hours after surgery in patients did not differ significantly between patients receiving paracetamol alone and those who received paracetamol with ondansetron. Also, the number of opioid consumed during the operation and in the postoperative phase were similar in patients receiving paracetamol alone and those who received paracetamol with ondansetron. In an interventional study conducted by Bhosale et al in the United States, ${ }^{19} 32$ patients were randomized into two groups of patients receiving paracetamol ( $4 \mathrm{~g}$ intravenous) plus ondansetron and those who received paracetamol $(4 \mathrm{mg}$ intravenous) with placebo. At the end of the operation, it was announced that the effect of ondansetron in the mix with paracetamol for controlling postoperative pain was greater than placebo compare with paracetamol. In our study, we have used greater sample size and we found that there was 
no difference in the effect of ondansetron in the mix with paracetamol.

In another interventional study conducted by Alipour et al in Iran, ${ }^{20}$ there were 336 patients in the six groups receiving ondansetron ( $4 \mathrm{mg}$ intravenous), paracetamol ( $2 \mathrm{mg} / \mathrm{kg}$ intravenous), granisetron ( $2 \mathrm{mg}$ ), lidocaine ( $40 \mathrm{mg}$ ), magnesium sulfate ( $2 \mathrm{mg}$ ), and placebo ( $5 \mathrm{~mL}$ normal saline) before surgery and showed that all drugs had a significant reduction in pain intensity versus placebo; however, granisetron and lidocaine had the most effective outcome. ${ }^{21}$ But in our study, the addition of ondansetron did not affect the reduction of pain.

In an experimental study conducted by Minville et al, ${ }^{22}$ two different protocols were tested on mouse samples after tibia bone fracture. In the first protocol, the mice were divided into four groups after the fracture of the tibia: intraperitoneal injection of paracetamol $30 \mathrm{mg} / \mathrm{kg}$, paracetamol $50 \mathrm{mg} / \mathrm{kg}$, paracetamol $100 \mathrm{mg} / \mathrm{kg}$, or saline. ${ }^{23}$

In the second protocol, paracetamol $100 \mathrm{mg} / \mathrm{kg}$ plus saline, paracetamol $100 \mathrm{mg} / \mathrm{kg}$ with ondansetron $2 \mathrm{mg} / \mathrm{kg}$ or saline alone were injected into the peritoneum. It was observed that the reduction in pain intensity for paracetamol was significantly greater than ondansetron. ${ }^{24}$ However, in our study, the efficacy of paracetamol was confirmed; though, ondansetron did not increase this efficacy.

In an interventional study conducted by Memis et al in Turkey, ${ }^{25} 20$ patients received paracetamol (1 $\mathrm{g}$ intravenous every 6 hours to 24 hours) and 20 placebo ( $100 \mathrm{~mL}$ normal saline intravenous every 6 hours to 24 hours). It was reported that paracetamol has a good analgesic effect in reducing postoperative pain, which has been shown in our study.

\section{Conclusion}

Based on the results of this study and their comparison with other studies conducted in this field, it is concluded that the addition of ondansetron to paracetamol has no more effect on reducing acute pain after abdominal surgery, so using it along with paracetamol is not recommended. At the end, it is recommended that further studies be conducted to confirm the findings of this study with a higher sample size and also to evaluate other methods of pain relief after surgery.

Ethical Approval and Consent to Participate

All procedures performed in this study involving human participants were in accordance with the ethical standards of the institutional and/or national research committee and with the 1964 Helsinki Declaration and its later amendments or comparable ethical standards.

This study was approved by the Research Ethics Committee, Board at the Azad University of Medical Sciences. (IR.IAU. TMU.REC.1395.260) on November 23, 2018 and was in accordance with the Helsinki principles.

\section{Authors' Contribution}

M.A. and F.G. conceptualized and designed the study, drafted the initial manuscript, and reviewed and revised the manuscript. M.N. and K.F. designed the data collection instruments, collected data, carried out the initial analy- ses, and reviewed and revised the manuscript. G.D. and S.D. coordinated and supervised data collection, and critically reviewed the manuscript for important intellectual content.

Conflict of Interest

None declared.

\section{References}

1 Mann E, Carr E. Pain management. Foundation studies for caring: using student-centred learning. Journal of Pain Management 2018;10:259

2 Shang AB, Gan TJ. Optimising postoperative pain management in the ambulatory patient. Drugs 2003;63(09):855-867

3 Beiranvand S, Moradkhani MR. Bupivacaine versus liposomal bupivacaine for pain control. Drug Res (Stuttg) 2018;68(07): 365-369

4 Beiranvand S, Karimi A, Vahabi S, Amin-Bidokhti A. Comparison of the mean minimum dose of bolus oxytocin for proper uterine contraction during cesarean section. Curr Clin Pharmacol 2019; 14(03):208-213

5 Gramke H-F, de Rijke JM, van Kleef M, et al. The prevalence of postoperative pain in a cross-sectional group of patients after day-case surgery in a university hospital. Clin J Pain 2007;23(06): 543-548

6 Moradkhani MR, Karimi A, Zarei Z, Vahabi S. The relationship between the phases of the menstrual cycle on the incidence and severity of headache after spinal anesthesia. Surg J (NY) 2019;5 (03): e126-e130

7 Samin J, Collange O, Pourtalès MC, Ravaz T, Calon B, Pottecher T. Assessment of quality in day-case hand surgery. Ann Fr Anesth Reanim 2009;28(09):735-742

8 Hassanzadeh-Kiabi F, Negahdari B. Antinociceptive synergistic interaction between Achillea millefolium and Origanum vulgare L. extract encapsulated in liposome in rat. Artif Cells Nanomed Biotechnol 2018;46(05):994-1000

9 Vahabi S, Karimi A, Ghanavati M. Comparison of complications between gender during spinal anesthesia. J Surg Oper Care 2018;3 (02):201

10 Robaux S, Coulibaly Y, Konaté B, et al. Impact of 2 strategies of analgesia on postoperative pain after emergency hand surgery performed on an ambulatory basis. Ann Fr Anesth Reanim 2003; 22(08):691-696

11 Vadivelu N, Mitra S, Narayan D. Recent advances in postoperative pain management. Yale J Biol Med 2010;83(01):11-25

12 Hasanzadeh-Kiabi F, Negahdari B. Applications of drug anesthesia in control chronic pain. J Invest Surg 2019;32(03):232-237

13 Beiranvand S, Vahabi S. Effect of local ropivacaine on hemodynamic responses in craniotomy patients. J Invest Surg 2018;31 (06):464-468

14 Miller RD, Pardo M. Basics of Anesthesia e-book. Netherlands: Elsevier Health Sciences; 2011

15 Trevor AJ, Katzung BG, Masters SB, Kruidering-Hall M. Pharmacology examination \& board review. New York, NY: McGraw-Hill Medical; 2010

16 Hasanzadeh-Kiabi F. Nano-drug for pain medicine. Drug Res (Stuttg) 2018;68(05):245-249

17 Champely S, Ekstrom C, Dalgaard P, Gill J, Weibelzahl S, Anandkumar A, Ford C, Volcic R, Volcic R, and De Rosario H. "pwr: Basic functions for power analysis". R package version 2017;1(01):665

18 Cohen J. Statistical Power. Analysis for the Behavioral Sciences. Hillsdale, NJ: Lawrence Erlbaum; 1988:273-406

19 Bhosale UA, Khobragade R, Naik C, Yegnanarayan R, Kale J. Randomized, double-blind, placebo-controlled study to investigate the pharmacodynamic interaction of 5-HT3 antagonist 
e318 Acute Postoperative Pain Aryafar et al.

ondansetron and paracetamol in postoperative patients operated in an ENT department under local anesthesia. J Basic Clin Physiol Pharmacol 2015;26(03):217-222

20 Alipour M, Tabari M, Alipour M. Paracetamol, ondansetron, granisetron, magnesium sulfate and lidocaine and reduced propofol injection pain. Iran Red Crescent Med J 2014;16(03):e16086

21 Saliminia A, Azimaraghi O, Javadi A, Abdoulahpoor M, Movafegh A. Comparison of granisetron and lidocaine on reducing injection pain of etomidate: a controlled randomized study. Rev Bras Anestesiol 2017;67(06):615-618

22 Minville V, Fourcade O, Mazoit JX, Girolami JP, Tack I. Ondansetron does not block paracetamol-induced analgesia in a mouse model of fracture pain. $\mathrm{Br}$ J Anaesth 2011;106(01):112-118
23 Alizadeh R, Mireskandari S-M, Azarshahin M, et al. Oral clonidine premedication reduces nausea and vomiting in children after appendectomy. Iran J Pediatr 2012;22(03): 399-403

24 Jokela R, Ahonen J, Seitsonen E, Marjakangas P, Korttila K. The influence of ondansetron on the analgesic effect of acetaminophen after laparoscopic hysterectomy. Clin Pharmacol Ther 2010; 87(06):672-678

25 Memis D, Inal MT, Kavalci G, Sezer A, Sut N. Intravenous paracetamol reduced the use of opioids, extubation time, and opioidrelated adverse effects after major surgery in intensive care unit. J Crit Care 2010;25(03):458-462 